\title{
Characterizing Super-Posters in a MOOC for Teachers' Professional Development
}

\author{
Fernanda Cesar Bonafini \\ The Pennsylvania State University
}

\begin{abstract}
Massive Open Online Courses (MOOCs) attract thousands of participants who each exercise autonomy by engaging with resources and with other participants to whatever degree they wish. When analyzing participants' patterns of engagement in MOOCs, it is possible to notice that certain participants exhibit high levels of participation, actively engaging with others in forums. This study focuses on characterizing these highly active participants and understanding their contributions back to the network in a MOOC designed for teachers' professional development. Connectivism is used as theoretical lens to describe super-posters' engagement in forums. Data from participants' demographics, click data, and forum posts are used to identify these highly active users. Qualitative content analysis is used to categorize the content of their posts, and social network analysis is used to represent their patterns of engagement. Results show that super-posters are generators of engagement, repurposing the content learned from the MOOC and feeding forward new resources to the network. Results present super-posters as representatives of participation inequality in forums, in which less than $1 \%$ of participants enrolled in the MOOC contributed the most to forums. Analysis of their behavior in forums reveals super-posters as the most prestigious and most influential nodes in the networks created by participants as they engage in forums. In some networks super-posters served as bridges, connecting people from different discussion threads and helping information to flow through the network. This study provides to MOOC designers and MOOC instructors a straightforward method to identify and classify superposters in any MOOC. Findings of this study could be used by MOOC designers and MOOC instructors to develop pedagogical interventions to give these participants a special role in the next MOOC cohort, which may foster engagement in MOOC forums and nurture the cyclical process of learning described in connectivism. Regarding implications for research, this study attends to the need for qualitative methods when analyzing participants' engagement in MOOC forums and contributes to our knowledge of participation inequality. It also extends the literature of superposters by showing their characterization in a MOOC focused on teachers' professional development.
\end{abstract}

Keywords: MOOCs for teachers, participation inequality in forums, super-posters, high active participants in MOOCs, most active users, MOOC forums, qualitative research.

Bonafini, F.C. (2018). Characterizing super-posters in a MOOC for teachers' professional development. Online Learning, 22(4), 89-108. doi:10.24059/olj.v22i4.1503 


\section{Characterizing Super-Posters in a MOOC for Teachers' Professional Development}

Massive Open Online Courses (MOOCs) attract thousands of participants who each exercise autonomy by engaging with resources and with other participants to whatever degree they wish. When analyzing participants' patterns of engagement in forums, it is possible to notice variations in levels of participants' engagement (e.g., Bozkurt \& Aydın, 2015; Dubosson \& Emad, 2015; Coetzee, Fox, Hearst, \& Hartmann, 2014; de Waard et al., 2011), in which certain participants present high levels of participation, actively engaging with others in forums (Wong, Pursel, Divinsky, \& Jansen, 2015; Huang, Dasgupta, Ghosh, Manning, \& Sanders, 2014). These top forum contributors, usually called "super-posters" (Huang et al., 2014, p. 1), open new discussion threads and reply to posts of others, helping to set the tone of the discussions. Their activity in forums has the potential to influence the subject that will be discussed as well as the network that will be formed as the result of participants' engagement in those discussions. Given the importance of these highly active forum participants, this study focuses on understanding and characterizing these participants and their contributions back to the network in a MOOC designed for teachers' professional development.

MOOCs for teachers have emerged as an affordable way to provide large-scale and freeof-charge professional development for professionals serving in K-12 settings (Kellogg, Booth, \& Oliver, 2014). They are designed to promote teachers' self-directed and flexible learning, peer support, and the opportunity to work from practice as teachers engage in discussions, share their practice, and contribute to the learning of others (Kleiman, Wolf, \& Frye, 2013). For teachers, these MOOCs afford opportunities to "improve their skills in the subject area, re-examine their teaching practices, and make instructional use of new approaches or tools" (Bonafini, 2017, p. 10).

\section{Review of Related Literature}

\section{Participants' Engagement in MOOC Forums}

In regular MOOCs and in MOOCs for teachers, participants engage with a variety of resources, such as online reading materials, videos, quizzes, simulations, and assessments. Discussion forums play an essential role in MOOCs in which participants reflect upon their interactions with resources, engage with others, and learn from different perspectives (Hollands \& Tirthali, 2014; Young, 2012). Participants' engagement in forums requires self-ownership of their path of learning (self-learning orientation), allowing them to decide which topics and people they will engage with (Mackness, Mak, Fai, \& Williams, 2010).

For the ones who participate in forums, this environment has the potential to help learners to develop a sense of belonging within the group (Lang, 2010) and a sense of community within the course (Hollands \& Tirthali, 2014). Forums have the potential to foster participants' reflection and connection of ideas (Gao, 2014), to host cooperation among participants (Coetzee, Fox, Hearst, \& Hartmann, 2014), and to promote collaborative thinking (Ruberg, Moore, \& Taylor, 1996), allowing participants to learn through the experiences of others (Young, 2012). Participants who engage in forums present higher satisfaction with respect to the MOOC (Ke \& Xie, 2009), and their engagement in forums may affect their likelihood of completing the MOOC (Bonafini, 2017; Bonafini, Chae, Park, \& Jablokow, 2017; Goldberg et al., 2015; Breslow et al., 2013; Kizilcec et al., 2013). For teachers, MOOC forums provide opportunities for them to engage with others, to learn from the practice of others, and to expand their own professional knowledge. Thus, 
it becomes crucial for MOOC researchers to understand and characterize the participants who contribute most to the forum ecology.

\section{Super-Posters' Engagement With MOOC Forums}

Although participation in forums is a voluntary activity, not all participants engage in forums in the same way (de Waard et al., 2011; Cormier \& Siemens, 2010). Some participants prefer just to observe what is happening in forums (passive learners), others prefer to contribute to some discussions (active learners), while others prefer to intensely engage in the forum ecology by opening discussion threads and posting in discussions created by others (high active learners).

Participation in MOOC forums can be described by the term participation inequality (Nielsen, 2006). According to Nielsen (2006), participation inequality means that participation tends to follow a 90-9-1 rule, in which " $90 \%$ of users are lurkers (i.e., read or observe, but don't contribute), $9 \%$ of users contribute from time to time, but other priorities dominate their time, [and] $1 \%$ of users participate a lot and account for most contributions" (p. 1). Participation inequality is a documented phenomenon that happens not only in forums for education purposes like in MOOCs but also in other environments, such as Wikipedia's contributors' forums, Amazon reviews, news groups, game forums, mailing lists, online communities, and so on (Haklay, 2016; Nielsen, 2006).

Huang et al. (2014) labeled the "highest-volume contributors" in MOOC forums superposters (p. 1). In their study, these authors examined the activity of forums from 44 Coursera MOOCs to identify the behavior of super-posters. They found a positive correlation between super-posters' forum behavior and their MOOC performance. Super-posters' high activity in forums "is positively correlated with higher activity from other forum users" (Huang et al., p. 8). Thus, super-posters play an important role in the quality of the course and the tone of the discussions. They do not silence other participants, and their engagement in forums brings "highvalue contributions and also correlates positively with activity and contribution quality from fellow students" (Huang et al., 2014, p. 9).

Dubosson and Emad (2015) also noticed that top active participants in a regular MOOC did not overwhelm the presence of others in forums. For these authors, top active participants "demonstrate a rather discreet presence" (p. 688), giving space to others to manifest themselves, keeping the democratic approach of MOOC forums. Although participation of high active learners has been explored in regular MOOCs, such as MOOCs offered by high-volume platforms (e.g., Coursera and edX), high active participants were not yet characterized in MOOCs designed for teachers' professional development. This is because MOOCs for professional development of teachers are relatively new in the MOOC offering spectrum. Due to its open enrollment and freeof-charge characteristics, MOOCs for teachers' professional development may appear attractive to professionals serving in K-12 settings who are seeking for alternative spaces to improve their professional skills to better teach their students. Understanding the characteristics of super-posters in a MOOC for teachers, their behaviors in forums, the content of their contributions to the network, and their role in the network created in forums can be crucial for MOOC designers and MOOC instructors in crafting further engagement in forums hosted not only in MOOCs for educators but also in MOOCs in general. As MOOC instructors learn more about how to characterize these highly active participants, MOOC instructors can encourage them to take leadership roles in forums, assisting the instruction team in fostering participants' engagement. Thus, this study aims to answer the following research questions: 
- Who are the super-posters in a MOOC focused on teachers' professional development of statistics teaching?

- What are super-posters' patterns of engagement?

- What is the content of super-posters contributions to forums?

- What is the role of super-posters in creating new discussions?

- How do super-posters position themselves within the network?

\section{Connectivism as a Theoretical Lens}

Connectivism highlights the potential of connections among people and content within the network (Siemens, 2004), such as MOOC participants establishing connections among themselves and promoting learning by their engagement throughout the network. Connectivism is used in this study as a theoretical lens to describe super-posters' engagement represented by their connections with peers in forums. The starting point in connectivism is the individual seeking learning. In this MOOC, teachers are seeking learning in terms of professional development. Participation in this MOOC is described by participants establishing and nurturing a diversity of connections. From this perspective, the learning process is cyclical (Kop \& Hill, 2008), wherein participants are able to learn by connecting to a network to share and find new information. The new knowledge that has been generated by participants can then be shared back through forums so that others can access it. Thus, the decision-making about establishing a connection is also part of participants' learning process.

\section{Types of Networked Learning Activities}

To describe the cyclical characteristic of learning in which participants connect to a network to find and share information, generate new knowledge, and then share this new knowledge back to the network, this study makes use of the three types of networked learning activities as proposed by Siemens and Downes (2011). They are aggregate, repurpose, and feedforward.

As a MOOC provides content embedded in its resources, participants start aggregating resources according to their main interest or main goal in the course. Aggregation may also come from resources that are shared by other participants as they interact in forums. In repurposing, participants will work with content created by somebody else and express their own understanding and knowledge that comes from those materials. Forums are usually the locus of this activity, where participants use materials generated in the aggregation activity as a source for repurposing. In feeding-forward, participants are encouraged to share their knowledge with other participants. The sharing process has the potential to enhance participants' networked learning since one participant may aggregate a piece of material previously shared by another participant, repurpose it, and feed it forward back to the network or share it to other audiences outside the MOOC environment.

\section{Study Context}

\section{Methods}

The context of this study is a MOOC for educators offered by a large U.S. university that has been specifically designed for mathematics teachers to learn about statistics teaching and the use of statistical investigations in teaching. This MOOC provided 12 discussion forums for participants, distributed as two forums per unit (over five units) plus an introductory forum and a 
project forum. The MOOC was officially available for six weeks, and the course platform remained accessible for an additional five weeks.

The MOOC was not designed under the connectivism perspective. Thus, connectivism is used in this study as a theoretical lens to describe super-posters' engagement as represented by their connections with peers in forums. The instruction team was comprised of the main instructor plus five assistants who actively engaged with participants through MOOC forums.

\section{Data Collection and Data Analysis}

This study makes use of quantitative data retrieved from participants' demographics (collected by the MOOC provider during participants' enrollment), click data (the recording of participants clicks while interacting with the MOOC), and qualitative data retrieved from the content of participants' forums posts. Content analysis and inductive coding (Thomas, 2003) were used to depict the content of participants' posts. Social Network Analysis (SNA) was used to depict the structure of the network produced by participants' interactions in forums. All data was collected from the same MOOC offered in the fall of 2015.

Content of participants' posts. Qualitative content analysis was used to show the content of participants' posts from 10 discussion forums. The introductory forum and the project forum were excluded from this analysis since they were additional forums beyond the core of the course. The researcher analyzed the content of participants' posts using an inductive coding process in which the categories emerged from the data (Hsieh \& Shannon, 2005; Mayring, 2000). Inductive coding is defined in this study as an approach "intended to aid an understanding of meaning in complex data through the development of summary themes or categories from the raw data" (Thomas, 2003, p. 3). This process allowed one segment of text to be coded into more than one category and permitted a segment of text to not be coded if it was not relevant to the research objectives (Thomas, 2003). Data from 207 forum posts were qualitatively analyzed using NVivo 11 Pro, which generated 831 coded excerpts.

Network structure. SNA was used show the structure of the network produced by participants as they interacted in forums. Data from participants' posts were fed into NodeXL Pro to construct the networks. NodeXL displays the network relationships by presenting a graph containing vertices (nodes in the network) and edges (connections between nodes). Nodes (dots) represent participant IDs, and edges (arrows) represent interactions between participants (i.e., one person replied to another). Squares represent clusters of participants, and self-loops represent isolated posts (i.e., participants who posted something and did not receive any reply from others). The Fruchterman-Reingold algorithm (Fruchterman \& Reingold, 1991) was used to display the networks. The Fruchterman-Reingold algorithm is a force-directed interactive algorithm in which, at each interaction, nodes connected by an edge are put together, and nodes not connected by an edge are put far from each other.

The overall metrics used to describe the networks (Hansen \& Smith, 2015) were number of vertices in the graph (vertices), number of edges without duplicates (unique edges), number of edges with duplicates (edges with duplicates), total number of edges in the graph (total edges), and number of edges that connect a vertex to itself (self-loops). In all networks, the directionality of the edges is represented by arrows. Centrality is defined by "the number of connections that an actor (a node) has with other actors" (Otte \& Rousseau, 2002, p. 447). The individual centrality measures used on the networks were in-degree (the quantity of arrows that go toward the person), out-degree (the quantity of arrows that go away from the person), betweenness-centrality (the 
"extent to which a node is connected to other nodes that are not connected to each other"; Soliman, Nasraoui, \& Cooper, 2016, p. 671), and closeness centrality (the "degree to which a node is near all other nodes in a network"; Soliman, Nasraoui, \& Cooper, 2016, p. 671).

\section{Results}

This section presents results of the analyses conducted to characterize super-posters in a MOOC for teachers' professional development. Discussion and conclusion are presented afterwards.

\section{Who Are the Super-Posters in a MOOC Focused on Teachers' Professional Development of Statistics Teaching?}

To identify super-posters, the total number of forum posts was cleaned by excluding posts from the MOOC instruction team. After removing the instruction team, the sample consisted of 2,095 posts generated by 328 active participants. In this study, super-posters were defined as a set of participants comprising the top $10 \%$ of forum participants, as shown in Table 1 . The criteria used to identify super-posters was a variation of the criteria used by Huang et al. (2014). While Huang et al. (2014, p. 3) used "a relative measure of contribution" for participants in forums to define super-posters' behavior, this study used the absolute number of posts generated by participants as a threshold to identify super-posters. In line with Huang et al. (2014), this study agrees that there are many different criteria that can be used as the threshold for defining superposters. Some other potential criteria are the top 5\% of participants in forums, the top $10 \%$ of participants in forums as defined by the ratio between the number of posts to general average of posts, and the top $10 \%$ of participants in forums as defined by the number of weekly posts.

Table 1

Super-Posters Participants Classification: A Set of Participants Comprising the Top 10\% of Forum Participants

\begin{tabular}{c|cc}
$\begin{array}{c}\text { Participant ID } \\
\text { numbers }\end{array}$ & $\begin{array}{c}\text { Number of } \\
\text { posts }\end{array}$ & $\begin{array}{c}\text { Percentage of the total } \\
\text { posts }\end{array}$ \\
\hline $\mathbf{4 4 0 9}$ & 76 & $3.63 \%$ \\
$\mathbf{3 6 3 1}$ & 48 & $2.29 \%$ \\
$\mathbf{4 3 4 6}$ & 46 & $2.20 \%$ \\
$\mathbf{4 5 1 3}$ & 37 & $1.77 \%$ \\
Total & $\mathbf{2 0 7}$ & $\mathbf{9 . 8 8 \%}$ \\
\hline
\end{tabular}

As presented in Table 1, there were four super-posters in this MOOC. Table 2, which displays participants' demographics, shows that three were from the United States (U.S.) and one was from the Philippines (PH). Only one super-poster was female. Each of the super-posters had between 17 and 21 years of professional experience, with one working as a K-12 teacher. Although participants in this MOOC presented a variety of education levels, $72 \%$ of participants indicated having a doctoral degree or a master's degree. Thus, the education level of super-posters is representative of the education level reported by the majority of participants in this MOOC. 
Table 2

Super-Posters' Demographics

\begin{tabular}{|c|c|c|c|c|c|}
\hline $\begin{array}{l}\text { Participant } \\
\text { ID numbers }\end{array}$ & $\begin{array}{l}\text { Level of } \\
\text { education }\end{array}$ & $\begin{array}{l}\text { Job } \\
\text { role }\end{array}$ & Country & Gender & $\begin{array}{c}\text { Years of } \\
\text { experience }\end{array}$ \\
\hline 4409 & $\begin{array}{c}\text { Master's } \\
\text { degree }\end{array}$ & $\begin{array}{c}\mathrm{K}-12 \\
\text { teacher }\end{array}$ & U.S. & Male & 18 \\
\hline 3631 & $\begin{array}{c}\text { Doctoral } \\
\text { degree }\end{array}$ & $\begin{array}{l}\text { College } \\
\text { professor }\end{array}$ & $\mathrm{PH}$ & Male & 15 \\
\hline 4346 & $\begin{array}{c}\text { Doctoral } \\
\text { degree }\end{array}$ & Statistician & U.S. & Female & 15 \\
\hline 4513 & $\begin{array}{c}\text { Doctoral } \\
\text { degree }\end{array}$ & $\begin{array}{l}\text { College } \\
\text { professor }\end{array}$ & U.S. & Male & 21 \\
\hline
\end{tabular}

The act of extracting the top forum participants in this MOOC is an example of participation inequality. A question that comes to mind is whether the distribution of participants activity in forums does follow Nielsen's $90-9-1 \%$ rule, in which $90 \%$ are lurkers, $9 \%$ make some contribution to forums, and $1 \%$ of participants contribute the most to forums. Note that the criterion used to define the threshold for being categorized as super-posters was their absolute number of posts comprising $10 \%$ of all posts in the forums. Here, the focus is on understanding how skewed the participation inequality in $\mathrm{MOOC}$ forums is. For that, the number of participants in each category of Nielsen's rule has to be identified. This MOOC enrolled 815 participants. Of these 815 participants, 328 engaged in forums posting at least once, 224 lurked the discussions, 263 dropped the course (i.e., ceased engagement with course materials and with others in forums), and four participants were considered the most active participants in forums, posting more than 30 times each. This implies that the proportions of participation inequality in this MOOC are 27.48-40.25$0.49 \%$ which differs from Nielsen's $90-9-1 \%$ rule, as shown in Figure 1.

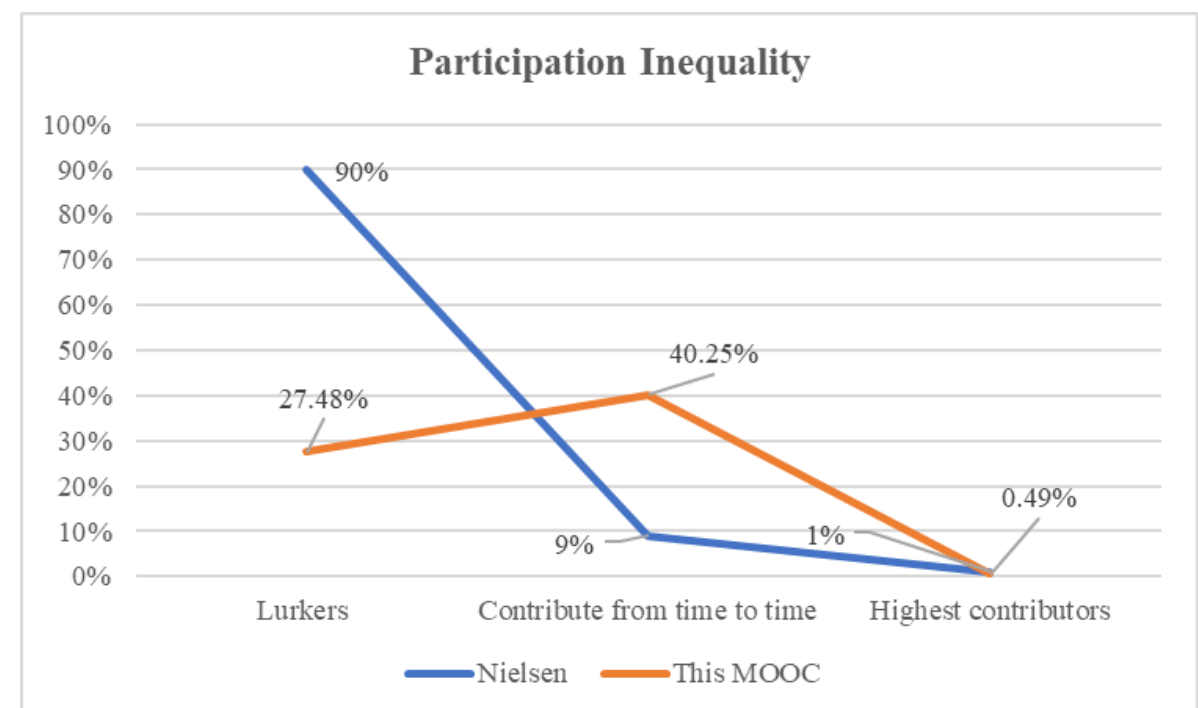

Figure 1. Comparison of participation inequality between Nielsen's role and participants in this MOOC. 
Figure 1 shows that $27.48 \%$ of total participants lurked in forums, which is a relatively small number when compared to Nielsen's rule (i.e., 90\%). A total of $40.25 \%$ of participants contributed infrequently to forums, which represents a higher number when compared to the $9 \%$ from Nielsen's rule. Only $0.49 \%$ were the top contributors in forums, which is less than half of what is suggested by Nielsen's rule (i.e., 1\%). This means that the distribution of participation inequality is still very skewed, with less than $0.5 \%$ contributing most of the knowledge generated by participants in forums.

Looking at the super-posters' characteristics shown on Table 2, notice that they were not representative of the intended population for this professional development (i.e., K-12 teachers). Moreover, the skewness in participation inequality was also present within super-posters group, in which only one participant was not from the United States, and only one participant was female. According to Haklay (2016), participation inequality is linked to "other social inequalities" (p. 40). In this case, participation inequality is also linked to country of origin and the gender of top participants.

\section{What Are Super-Posters' Patterns of Engagement?}

The patterns of engagement of the four super-posters were very similar to each other with respect to creation of discussions threads. As shown in Figure 2, the average number of discussion threads created among them was 12 discussion threads. Super-posters 3631 and 4346 created more discussion threads than the super-poster average, while super-poster 4409 and super-poster 4513 created fewer discussion threads than the super-poster average.

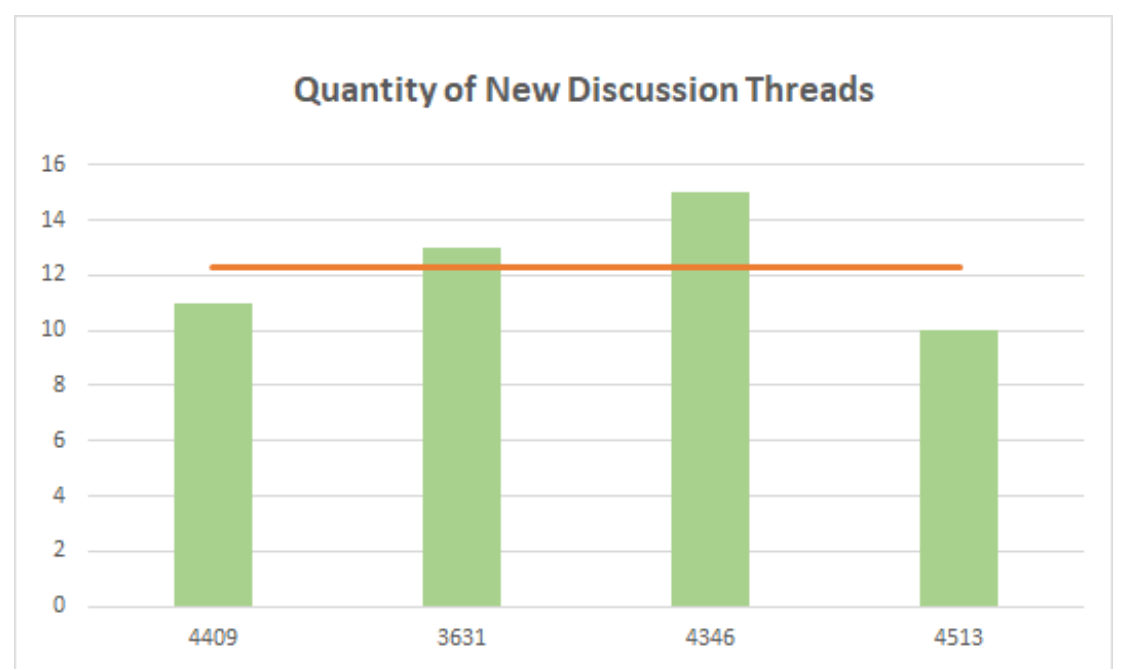

Figure 2. Quantity of new discussion threads created among super-posters.

By creating new discussion threads, these super-posters provided opportunities for other participants to aggregate content embedded in their messages, which could be later repurposed and fed forward by other participants. For example, super-poster 4409 opened a new discussion thread by sharing his view about the importance and potential of the Pepsi versus Coke activity (a MOOC material) in providing opportunities for students to get involved with data collection, data organization, and notions of randomness and bias. Participant 3776 joined the discussion thread by expressing agreement with the ideas of super-poster 4409 and built on super-poster 4409's post by sharing his views on how the Pepsi versus Coke activity could be transformed in order to 
provide students with an even more realistic context when working with statistical investigations by granting students the decision about how to design the experiment.

Participant 3704 joined the thread created by super-poster 4409 by replying to participant 3776 expressing agreement with participant 3776's suggestion of leaving students to figure out the design of the statistical experiment. In her post, participant 3704 stated that she has taken this approach in her class: "I have done a similar exercise in class in the past with designing an experiment to test one student's claim that they can tell the difference between Coke and Pepsi." Participant 4656 joined the thread created by super-poster 4409 by replying to participant 3704 . By doing so, participant 4656 shared with others in this thread that she "would add time into class to have students [to] choose which products [they will] test and [to] design the study to minimize bias." Participant 4656 also made use of forums to share with others in this thread how she teaches her students about sample methods. She stated, "I often start my unit on sampling methods and design with my seniors by having them design both a survey and an experiment to choose our school's favorite potato chip. Each year we end up with completely different designs."

Regarding replies to others, Figure 3 shows an average of 39 posts among the super-posters group. Participant 4409 presented a much higher number of posts when compared to other superposters (Figure 3). The number of replies to other participants emerges as an essential element in differentiating one super-poster above other members of the super-posters group. Due to this behavior, participant 4409 was labeled as the super-poster master, acting as a leader of engagement when compared to contributions from other super-posters.

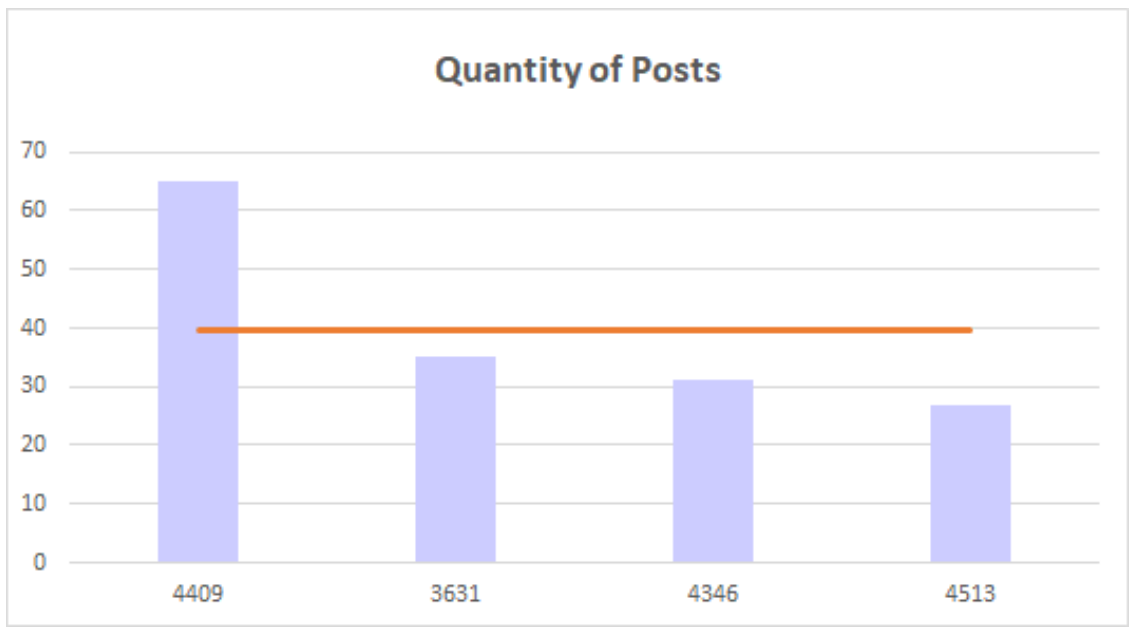

Figure 3. Quantity of posts among super-posters.

When observing their pattern of creating discussion threads through time, as shown in Figure 4, it is possible to note that super-posters created more discussion threads earlier in the course, with discussion thread creation hitting a peak on 10/11/15. Super-posters did not evenly distribute their discussion thread creations throughout the MOOC's duration. Figure 4 shows that super-posters 4409, 4346, and 4513 presented weekly gaps in creating new discussion threads, while participant 3631 didn't create any discussion threads for almost a month. Alternatively, participant 3631 helped to extend the life span of active engagement by creating seven new discussion threads during the MOOC extension period, where the platform was opened but no new content was offered by the MOOC provider. 


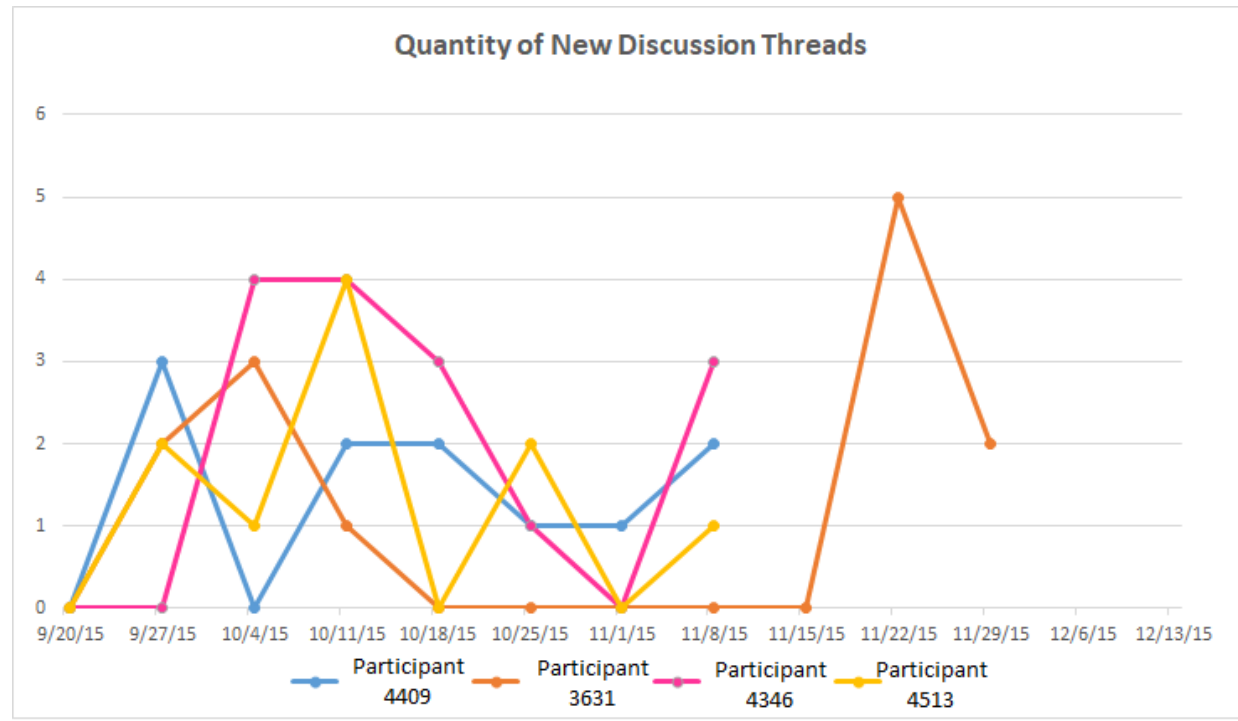

Figure 4. Quantity of weekly new discussion threads created by super-posters.

Super-posters' weekly pattern of posts (shown in Figure 5) had peaks (31 posts in Week 2) and valleys (one post in Week 10). Only super-posters 4513 and 3631 continued posting during the extension period of this professional development.

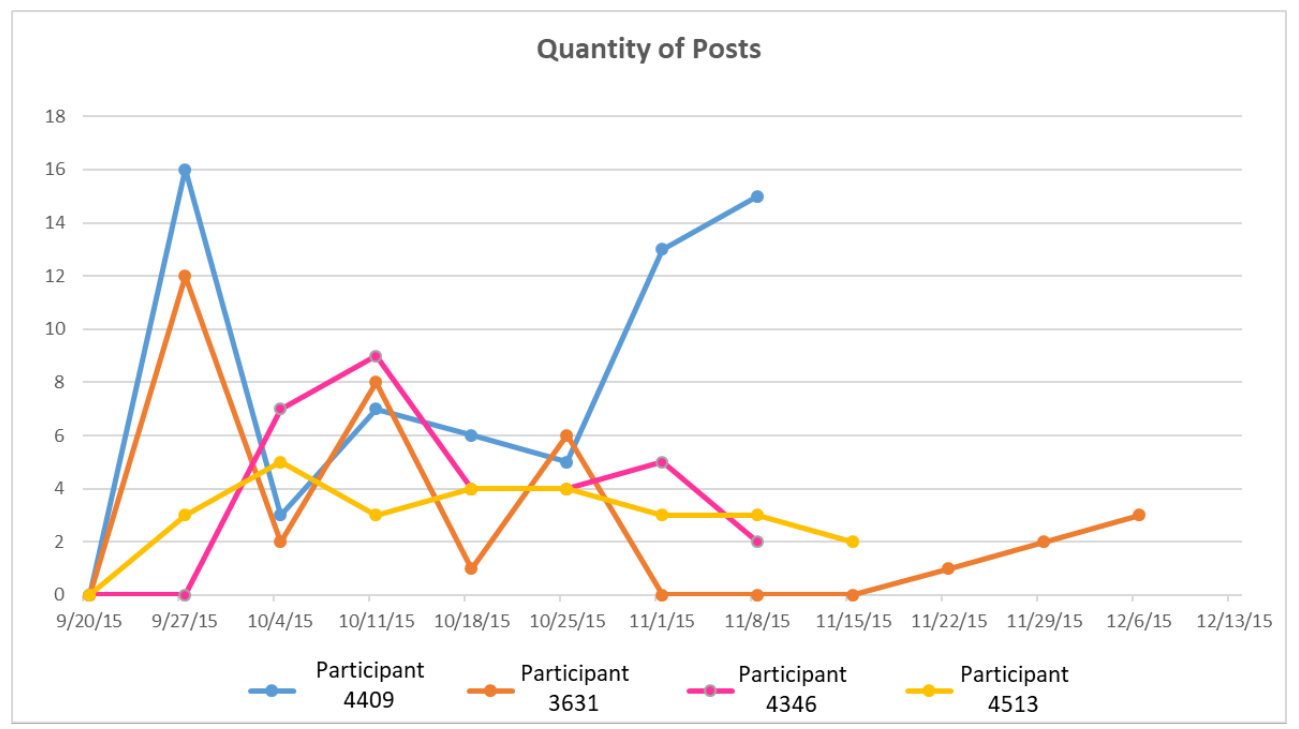

Figure 5. Quantity of weekly posts among super-posters.

Although participants were free to post in forums without any limitation regarding their profiles or quantity of posts, participation inequality can also be seen through time (temporal scale), in which super-posters created new discussion threads and posted more posts at the beginning of the MOOC. Super-posters' engagement varied from week to week, showing that super-posters did not sustain the same level of engagement as the MOOC progressed. 


\section{What Is the Content of Super-Posters' Contributions to Forums?}

Results from qualitative analysis on forum posts show that super-posters mostly used forums to share their perspectives about MOOC materials (107 coded excerpts) and about K-12 students learning or advancing their knowledge of statistics (221 coded excerpts). An example of super-posters sharing in forums their perspectives about MOOC materials is the post of superposter 3631, who stated, "I have explored Gapminder [a MOOC resource] but I do not know what is the scale of the values vs actual data in the table." An example of super-posters sharing in forums their perspectives on K-12 students learning or advancing their knowledge of statistics is the post of super-poster 4409, who stated, "As I viewed the Gapminder [a MOOC resource], I was struck by the richness of the data and how it would impact my students' learning and probable quest to a better understanding of conceptual statistics."

Besides these two main themes, super-posters used forums to describe their classroom activities and/or their classroom norms (75 coded excerpts), share their inquiry about the subject of statistics (52 coded excerpts), express their insecurities related to their experience with statistics teaching (88 coded excerpts), share their statement of opinions (79 coded excerpts), and express their intentions and use of technology in their classes (42 coded excerpts). With respect to other participants, super-posters mainly displayed concordance with ideas of others in forums (131 coded excerpts). For instance, super-poster 4409 stated, "Your suggestion goes right to this aspect of my teaching. This time though, I really would do it step by step myself before I would model it to them [students] and ask them [students] to do it the same way as I did."

Super-posters also used forums to recommend resources to other participants. An example is the post of super-poster 4346, who stated, "The new crop of popular statistics websites and social media forums such as Nate Silver's FiveThirtyEight.com (https://fivethirtyeight.com/). These types of resources may engage students by helping them to see statistics in their everyday world." All super-posters, with exception of super-poster 4346, posted in forums their intentions of implementing the learning acquired through this MOOC (21 coded excerpts). For example, superposter 4513, referring to a statistical technology tool available in this MOOC, posted, "I had never used it [the statistical technology tool] before, but I'm going to introduce it to my students next week!"

\section{What Is the Role of Super-Posters in Creating New Discussions?}

In addition to analyzing the content of discussion posts, as shown in the previous section, it is important to know the role of super-posters in creating new discussions in forums. In this study, super-posters not only contributed to the forum ecology by posting in discussions of others but also opened 49 new discussion threads, which represents $7.58 \%$ of the total number of discussion threads created in this MOOC, as shown in Table 3. The discussion threads initiated by super-posters hosted seven posts on average. Super-posters initiated these discussions by presenting their repurposing and feeding forward of materials provided by this professional development. For example, super-poster 3631, referring to the steps of a statistical investigation, a resource offered by the MOOC provider, opened a discussion by stating the following:

I observe in the posting of questions [in a statistical investigation], the questions are not expressed in terms of the 'what' aspect in research. It could be better if it [would be] stated like this: what is the mode of transportation of students in going to school? At least from here, you identify that the variable is mode of transportation. 
Table 3

Number of Discussions Initiated by Super-Posters

\begin{tabular}{|c|c|c|}
\hline $\begin{array}{c}\text { Super-poster } \\
\text { ID }\end{array}$ & $\begin{array}{c}\text { Number of discussion threads } \\
\text { initiated by the super-posters }\end{array}$ & $\begin{array}{c}\text { \% of total } \\
\text { discussion threads }\end{array}$ \\
\hline 4346 & 15 & $2.32 \%$ \\
\hline 3631 & 13 & $2.01 \%$ \\
\hline 4409 & 11 & $1.70 \%$ \\
\hline 4513 & 10 & $1.55 \%$ \\
\hline Total & $\mathbf{4 9}$ & $\mathbf{7 . 5 8 \%}$ \\
\hline
\end{tabular}

Super-posters' feeding forward mainly consisted of participants' reflections and opinions about the resources provided by this professional development.

\section{How Do Super-Posters Position Themselves Within the Network?}

For a full understanding of the characterization of super-posters in this MOOC, it is important to know how super-posters are positioned within the networks created by MOOC participants as they engage with others in forums. Figure 6 shows the network of participants' engagement in forums by units highlighting super-posters' connections (in thicker lines) within these networks. Table 4 exhibits the NodeXL's overall metrics for each network. Table 4 shows that the discussion forums from Unit 1 hosted the highest number of participants (196 vertices), the highest number of reciprocated communication between vertices pairs (69 edges with duplicates), and the highest number of participants' posts that did not receive a reply (80 selfloops).

Table 4

NodeXL Overall Metrics for the Networks Created by Participants at Each Unit on This MOOC

\begin{tabular}{|c|c|c|c|c|c|c|}
\hline & Unit 0 & Unit 1 & Unit 2 & Unit 3 & Unit 4 & Unit 5 \\
\hline Vertices & 144 & 196 & 119 & 90 & 75 & 74 \\
\hline Unique edges & 182 & 359 & 242 & 153 & 182 & 127 \\
\hline Edges with duplicates & 14 & 69 & 19 & 32 & 27 & 24 \\
\hline Total edges & 196 & 428 & 261 & 185 & 209 & 151 \\
\hline Self-loops & 12 & 80 & 15 & 22 & 27 & 3 \\
\hline
\end{tabular}

The individual centrality measures used in this study are presented in Table 5. Analyzing the centrality measures of participants who engaged in discussions throughout this MOOC (Table 5), it is possible to notice that super-poster 4409 was the most prestigious participant in discussions from Units 1, 2, 4, and 5, since this node presented the highest in-degree measure (number of arrows that link other people to super-poster 4409's node). By having more arrows leaving superposter 4513's nodes, he was considered an influential node in the networks from Units 1 and 2. Similarly, super-poster 4346 was the most influential one in the network from Unit 5. Super-poster 4513 worked as a bridge in discussions from Unit 2 (betweenness centrality $=6240.28$ ). This bridge can be seen by the arrows connecting groups in the network of forums from Unit 2 (Figure 6). Super-poster 4409 also worked as a bridge in discussions from Units 4 and 5 (betweenness 
centrality $=2266.33$ and 2066.37 , respectively). Super-poster 4513 was the nearest node to all other nodes in discussions from Units 1 and 2 (closeness centrality $=0.006$ and 0.004 , respectively). Super-poster 4409 was the nearest node to all other nodes in discussions from Units 3,4 , and 5 (closeness centrality $=0.031,0.008$, and 0.007 , respectively).

Surprisingly, the interactions of super-poster 3631 were not shown in the centrality measurements from Table 5. Although, participant 3631 was considered a super-poster in this study, his interactions in this MOOC seem to have been diluted throughout the whole course, which may have contributed to his centrality measurements not being as high as his peers. On the other hand, some MOOC participants who were not classified as super-posters made a mark in some forums, as was the case of participant 3304 (a college professor) and participant 4319 (K-12 teacher) as shown in Table 5.

Table 5

Individual Centrality Measures for MOOC Unit Networks

\begin{tabular}{|c|c|c|c|c|c|c|}
\hline & Unit 0 & Unit 1 & Unit 2 & Unit 3 & Unit 4 & Unit 5 \\
\hline In-degree & $\begin{array}{c}\text { Super-poster } \\
4329 \text { had the } \\
\text { highest in- } \\
\text { degree }=25\end{array}$ & $\begin{array}{c}\text { Super-poster } \\
4409 \text { had the } \\
\text { highest in- } \\
\text { degree }=9\end{array}$ & $\begin{array}{c}\text { Super-poster } \\
4409 \text { had the } \\
\text { highest in- } \\
\text { degree }=7\end{array}$ & $\begin{array}{c}\text { Super-poster } \\
3304 \text { had the } \\
\text { highest in- } \\
\text { degree }=11\end{array}$ & $\begin{array}{c}\text { Super-poster } \\
4409 \text { had the } \\
\text { highest in- } \\
\text { degree }=15\end{array}$ & $\begin{array}{c}\text { Super-poster } \\
4409 \text { had the } \\
\text { highest in- } \\
\text { degree }=12\end{array}$ \\
\hline Out-degree & $\begin{array}{c}\text { Super-poster } \\
3128 \text { had the } \\
\text { highest out- } \\
\text { degree }=7\end{array}$ & $\begin{array}{l}\text { Super-poster } \\
4513 \text { had the } \\
\text { highest out- } \\
\text { degree }=15\end{array}$ & $\begin{array}{l}\text { Super-poster } \\
4513 \text { had the } \\
\text { highest out- } \\
\text { degree }=29\end{array}$ & $\begin{array}{l}\text { Super-poster } \\
4622 \text { had the } \\
\text { highest out- } \\
\text { degree }=11\end{array}$ & $\begin{array}{l}\text { Super-poster } \\
4514 \text { had the } \\
\text { highest out- } \\
\text { degree }=21\end{array}$ & $\begin{array}{l}\text { Super-poster } \\
4346 \text { had the } \\
\text { highest out- } \\
\text { degree }=14\end{array}$ \\
\hline $\begin{array}{c}\text { Betweenness } \\
\text { centrality }\end{array}$ & $\begin{array}{c}\text { Super-poster } \\
4319 \text { had the } \\
\text { highest } \\
\text { betweenness } \\
\text { centrality }= \\
4975.225\end{array}$ & $\begin{array}{c}\text { Super-poster } \\
4537 \text { had the } \\
\text { highest } \\
\text { betweenness } \\
\text { centrality = } \\
1402.044\end{array}$ & $\begin{array}{c}\text { Super-poster } \\
4513 \text { had the } \\
\text { highest } \\
\text { betweenness } \\
\text { centrality = } \\
6240.279\end{array}$ & $\begin{array}{c}\text { Super-poster } \\
3304 \text { had the } \\
\text { highest } \\
\text { betweenness } \\
\text { centrality = } \\
424.129\end{array}$ & $\begin{array}{c}\text { Super-poster } \\
4409 \text { had the } \\
\text { highest } \\
\text { betweenness } \\
\text { centrality = } \\
2266.326\end{array}$ & $\begin{array}{c}\text { Super-poster } \\
4409 \text { had the } \\
\text { highest } \\
\text { betweenness } \\
\text { centrality = } \\
2066.367\end{array}$ \\
\hline $\begin{array}{l}\text { Closeness } \\
\text { centrality }\end{array}$ & $\begin{array}{c}\text { Super-poster } \\
4319 \text { had the } \\
\text { highest } \\
\text { closeness } \\
\text { centrality = } \\
0.004\end{array}$ & $\begin{array}{c}\text { Super-poster } \\
4513 \text { had the } \\
\text { highest } \\
\text { closeness } \\
\text { centrality = } \\
0.006\end{array}$ & $\begin{array}{c}\text { Super-poster } \\
4513 \text { had the } \\
\text { highest } \\
\text { closeness } \\
\text { centrality }= \\
0.004\end{array}$ & $\begin{array}{c}\text { Super-poster } \\
4409 \text { had the } \\
\text { highest } \\
\text { closeness } \\
\text { centrality = } \\
0.031\end{array}$ & $\begin{array}{c}\text { Super-poster } \\
4409 \text { had the } \\
\text { highest } \\
\text { closeness } \\
\text { centrality }= \\
0.008\end{array}$ & $\begin{array}{c}\text { Super-poster } \\
4409 \text { had the } \\
\text { highest } \\
\text { closeness } \\
\text { centrality = } \\
0.007\end{array}$ \\
\hline
\end{tabular}




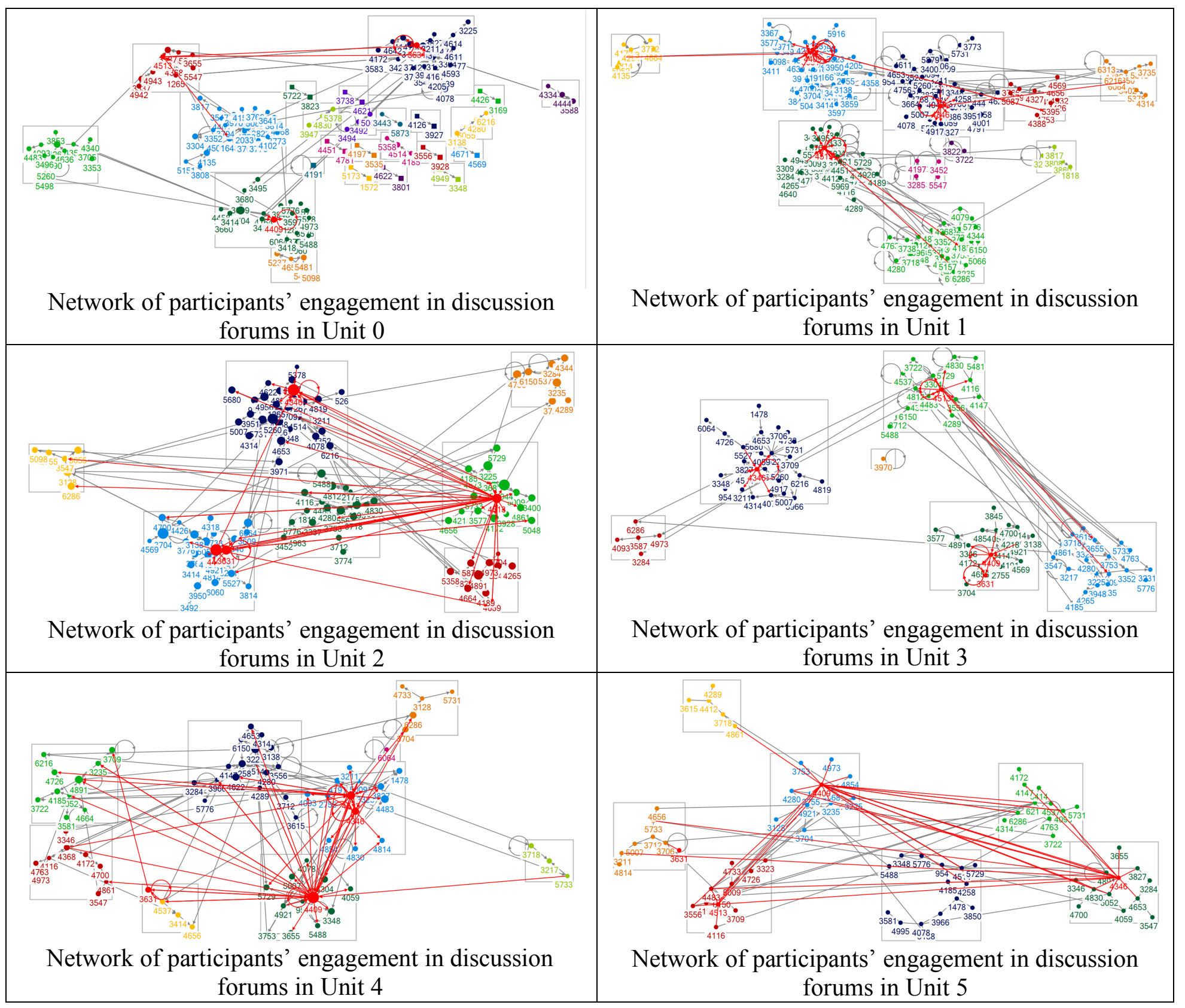

Figure 6. Network of participants' engagement in discussion forums by MOOC units. 


\section{Discussion and Conclusions}

This paper characterizes highly active participants, also known as super-posters, by analyzing their demographics, their engagement pattern in forums, and the content and structure of their posts. By investigating super-posters in a MOOC for teachers' professional development, this study showed that super-posters are highly qualified participants with strong academic backgrounds who have an active presence in the MOOC, as evidenced by their creation of new discussions and their replies to the posts of other participants. Super-posters expanded the network as they created new discussion threads that were populated by further posts from themselves and from other participants. These discussion threads increased interactivity among MOOC participants in forums represented by a surplus of 354 posts.

As they opened new discussion threads and replied to discussions created by others, superposters contributed to the definition of the content of $9.88 \%$ of all discussions in this MOOC. In terms of the network, they contributed by creating new nodes in it as they shared their reflections about the resources provided by this professional development. By sharing their practice through the discussion forums, super-posters opened doors for other participants to aggregate content embedded in their messages, which could be later repurposed and fed forward by other individuals (inside or outside this MOOC).

Results from qualitative analysis on forum posts showed that super-posters used forums for a variety of purposes. They shared in forums their perspectives about MOOC materials, their views about the importance of K-12 students learning statistics, their classroom activities, their insecurities about statistics teaching, and extra resources. The content of their posts was aligned to the course goal, and their participation in forums showed that super-posters were committed to contributing to the network. By engaging in forums, super-posters repurposed the content learned in this MOOC by sharing their experiences with others in forums.

Analyzing the ecology of forums represented through SNA, it was possible to notice the leadership of interactions hosted by super-poster 4409 and super-poster 4513. Super-poster 4409's leadership was also evidenced through the structure of his interactions in forums, in which he was the most prestigious node in four of the six networks. Super-poster 4513 was the most influential participant in two of the six networks (having the highest out-degree measure). Super-poster 4513's out-degree measure represents his ability to connect and potentially influence others in these networks (Russo \& Koesten, 2005). Super-posters 4513 and 4409 worked as bridges in forums in Units 2, 4, and 5, establishing connections with all groups in this network. As the nodes with the highest betweenness centrality in those units, these super-posters had the chance to work as brokers (Everetta \& Valente, 2016) connecting two separate groups within those respective networks. Super-posters 4513 and 4409 also had the highest closeness centrality in the networks, meaning that their nodes were near to other individuals in those networks (Dey \& Roy, 2016, p. 243). Thus, a question that emerges from the results is whether super-posters could be considered model participants in this MOOC.

The findings of Huang et al. (2014) state that "superposters can, ideally, be model participants" (p. 2) in MOOCs. Huang and colleagues highlight the benefits of super-posters' participation in forums as participants who start new conversations contributing to an increase of participation in forums, participants who inspire others by example of their interactions, and participants who support MOOC staff in answering questions of other participants. This study agrees with the findings of Huang et al. (2014) with respect to the benefits of super-posters 
contributing to an increase in participation in forums. However, in this MOOC super-posters should not be considered model participants.

This is because only one super-poster in this study (participant 4409) represented the target audience of this MOOC (i.e., K-12 teachers). For super-posters to have been considered model participants in this MOOC that was designed for K-12 teachers' professional development in statistics teaching, they should have been $\mathrm{K}-12$ teachers. This finding is aligned with the literature of participation inequality that states that top participants are in fact outliers, not being "representative of the overall population" (Haklay, 2016, p. 39). To have K-12 teachers acting as super-posters in this MOOC would imply that these K-12 teachers were leading the interactions in forums and leading their own professional development.

In contrast, super-posters can be considered models of participation in this MOOC. Their actions in forums increased interactivity in this MOOC. They contributed to the network with content aligned to the MOOC's goals. As they created discussions and/or posted in discussions created by others, they repurposed the content they learned in this MOOC by sharing their experiences with others.

Knowing that super-posters were not model participants in this MOOC, a question that comes to mind is whether it is possible to overcome the skewed distribution of participation inequality and give a more significant voice to the target audience of this MOOC. According to Nielsen (2006), participation inequality cannot be completely eliminated. However, it is possible to "shape the inequality curve's angle" (Nielsen, 2006, p. 4). Recommendations are for MOOC providers to make it easy for participants to contribute in forums. As suggested by Nielsen (2006), the creation of templates for forum participation, the use of rewards for the participants who actively engage in forums, and the promotion of high-quality contributions in forums can help to balance participation inequality. The implementation of badges (e.g., Anderson, Huttenlocher, Kleinberg, \& Leskovec, 2014) and/or gamification (e.g., Bozkurt \& Aydın, 2015) has been shown to increase forum engagement and may be helpful in rebalancing participation inequality in forums; however, more research is necessary.

This study provides MOOC designers and instructors with a straightforward method to identify and classify super-posters. Given the importance of participants' engagement in forums and the impact that super-posters have on engagement, identifying super-posters emerges as an important consideration. Once it is known who these super-posters are and the types of contributions they can make to the network, MOOC instructors can invite these participants to be part of the MOOC instruction team. In doing so, super-posters can act as forum leaders or forum mentors, thus increasing the interparticipant activity in forums and sharing additional resources that could be incorporated into the next MOOC offering. Regarding implications for research, this study extends the literature of super-posters (Huang et al., 2014) and participation inequality (Haklay, 2016; Neilsen, 2006) by showing the characterization of super-posters in a MOOC focused on teachers' professional development. It also shows that the work of super-posters has the potential to foster the cyclical process of learning in a MOOC as described by connectivism.

\section{Limitations and Future Work}

The findings of this study make contributions to MOOC designers and MOOC instructors by providing a straightforward method to identify and classify super-posters in any MOOC. However, these findings face some limitations. One limitation resides in the analysis of only one offering of this MOOC comprising 10 discussion forums. Although this MOOC had hundreds of 
active participants who actively contributed to forum discussions, the findings may not be generalizable to other professional development MOOCs. To overcome this limitation, it is suggested to investigate the role of super-posters in multiple cohorts of the same MOOC. Another limitation is related to the type of participants enrolled in this MOOC. As a MOOC for teachers' professional development, participants in this MOOC were highly qualified, and they might have had more self-regulation skills, making them more likely to interact in forums than participants who engage in regular MOOCs. To overcome this limitation, it is recommended that the design and analyses used in this study be replicated in different MOOCs for teachers' professional development - for example, MOOCs focusing on pedagogical approaches for mathematics, English, and science teaching. This study showed participation inequality in a MOOC for teachers' professional development. In future work, it will be interesting to investigate the motivations for regular participants to become super-posters and the process that creates super-posters in a MOOC.

\section{Acknowledgments}

I would like to thank the MOOC instruction team for providing the data that made this analysis possible, Dr. Rose M. Zbiek for the productive discussions about super-posters, Joshua Fritsch for the discussions and comments on previous versions of this manuscript, and the reviewers for their helpful comments and suggestions. 


\section{References}

Anderson, A., Huttenlocher, D., Kleinberg, J., \& Leskovec, J. (2014). Engaging with massive online courses. In C. W. Chung et al. (Eds.), 23rd International Conference on World Wide Web (WWW'14), (pp. 687-698). Seoul, Korea

Bonafini, F. (2017). The effects of participants' engagement with videos and forums in a MOOC for teachers' professional development. Open Praxis, 9(4), 433-447. http://dx.doi.org/10.5944/openpraxis.9.4.637

Bonafini, F. C., Chae, C., Park, E., \& Jablokow, K. W. (2017). How much does student engagement with videos and forums in a MOOC affect their achievement? Online Learning, 21(4), 223-240. doi:10.24059/olj.v21i4.1270

Bozkurt, A., \& Aydın, C. H. (2015). Satisfaction, preferences and problems of a MOOC participants. Proceedings of the Association for Educational Communications and Technology (AECT) 2015 International Convention (pp. 35-41). November 3-7, 2015, Indianapolis, IN.

Breslow, L., Pritchard, D. E., Deboer, J., Stump, G. S., Ho, A. D., \& Seaton, D. T. (2013). Studying learning in the worldwide classroom: Research into edX's first MOOC. Research \& Practice in Assessment, 8(1), 13-25.

Coetzee, D., Fox, A., Hearst, M. A., \& Hartmann, B. (2014). Should your MOOC forum use a reputation system? Proceedings of the 17th ACM Conference on Computer Supported Cooperative Work \& Social Computing CSCW 2014 (pp. 1176-1187). New York: ACM Press.

Cormier, D., \& Siemens, G. (2010). The open course: Through the open door-open courses as research, learning, and engagement. Educause Review Online, 45(4), 30-32.

Dey, P., \& Roy, S. (2016). Social network analysis. In N. Meghanathan (Ed.), Advanced methods for complex network analysis (pp. 237-265). Hershey, PA: IGI Global.

de Waard, I., Abajian, S. C., Gallagher, M. S., Hogue, R. J., Keskin, N. O., Koutropoulos, A., \& Rodriguez, C. O. (2011). Using mLearning and MOOCs to understand chaos, emergence, and complexity in education. The International Review of Research in Open and Distance Learning, 12(7), 94-115. Retrieved from http://www.irrodl.org/index.php/irrodl/article/view/1046/2026

Dubosson, M., \& Emad, S. (2015). The forum community, the connectivist element of an xMOOC. Universal Journal of Educational Research, 3(10), 680-690. doi:10.13189/ujer.2015.031004

Everetta, M. G., \& Valente, T. M. (2016). Bridging, brokerage and betweenness. Social Networks, 44, 202-208. doi:10.1016/j.socnet.2015.09.001

Fruchterman, T. M. J., \& Reingold, E. M. (1991). Graph drawing by force-directed placement. Software-Practice and Experience, 21, 1129-1164. Retrieved from http://www.mathe2.unibayreuth.de/axel/papers/reingold:graph_drawing_by_force_directed_placement.pdf 
Gao, F. (2014). Exploring the use of discussion strategies and labels in asynchronous online discussion. Online Learning, 18(3). http://dx.doi.org/10.24059/olj.v18i3.460

Goldberg, L. R., Bell, E., King, C., O’Mara, C., McInerney, F., Robinson, A., \& Vickers, J. (2015). Relationship between participants' level of education and engagement in their completion of the understanding dementia massive open online course. BMC Medical Education, 15(1), 60. doi:10.1186/s12909-015-0344-z.

Haklay, M. (2016). Why is participation inequality important? In C. Capineri, M. Haklay, H. Huang, V. Antoniou, J. Kettunen, F. Ostermann, \& R. Purves (Eds.), European handbook of crowdsourced geographic information. London: Ubiquity Press.

Hansen, D., \& Smith, M. (2015). How to use NodeXL. In J. Golbeck (Ed.), Introduction to social media investigation (pp. 237-253). Watham, MA: Elsevier Science.

Hollands, F., \& Tirthali, D. (2014). MOOCs: Expectations and reality. Retrieved from http://www.academicpartnerships.com/sites/default/files/MOOCs_Expectations and Rea lity.pdf

Hsieh, H., \& Shannon, S. E. (2005). Three approaches to qualitative content analysis. Qualitative Health Research, 15(9), 1277-1288. doi:10.1177/1049732305276687.

Huang, J., Dasgupta, A., Ghosh, A., Manning, J., \& Sanders, M. (2014). Superposter behavior in MOOC forums. In Proceedings of the First ACM Conference on Learning@Scale (L@S). doi:10.1145/2556325.2566249

Ke, F., \& Xie, K. (2009). Online discussion design on adult students' learning perceptions and patterns of online interaction. In C. O'Malley, D. Suthers, P. Reimann, \& A. Dimitracopoulou (Eds.), Proceedings of the International Conference of ComputerSupported Collaborative Learning, 1 (pp. 219-226). Rhodes, Greece. Island of Rhodes: International Society of the Learning Sciences.

Kellogg, S., Booth, S., \& Oliver, K. (2014). A social network perspective on peer supported learning in MOOCs for educators. International Review of Research in Open and Distributed Learning, 15(5).

Kizilcec, R. F., Piech, C., \& Schneider, E. (2013). Deconstructing disengagement: Analyzing learner subpopulations in massive open online courses. In Proceedings of the Third International Conference on Learning Analytics and Knowledge (pp. 170-179). New York: ACM. Retrieved from http://web.stanford.edu/ cpiech/bio/papers/deconstructingDisengagement.pdf

Kleinman, G., Wolf, M., \& Frye, D. (2013). The digital learning transition MOOC for educators: Exploring a scalable approach to professional development. Retrieved from http://all4ed.org/reports-factsheets/the-digital-learning-transition-mooc-for-educatorsexploring-a-scalable-approach-to-professional-development/

Kop, R., \& Hill, A. (2008). Connectivism: Learning theory of the future or vestige of the past? The International Review of Research in Open and Distance Learning, 9(3).

Lang, Q. C. (2010). Analysing high school students' participation and interaction in an asynchronous online project-based learning environment. Australasian Journal of Educational Technology, 26(3), 327-340. 
Mackness, J., Mak, S. F. J., \& Williams, R. (2010). The ideals and reality of participating in a MOOC. In L. Dirckinck-Holmfeld, V. Hodgson, C. Jones, M. de Laat, D. McConnell, \& T. Ryberg (Eds.), Proceedings of the 7th International Conference on Networked Learning (pp. 266-274). Aarlborg, DK. Retrieved from http://www.lancs.ac.uk/fss/organisations/netlc/past/nlc2010/abstracts/Mackness.html

Mayring, P. (2000). Qualitative content analysis. Forum Qualitative Sozialforschung/Forum: Qualitative Social Research, 1(2). Retrieved from http://www.qualitativeresearch.net/index.php/fqs/article/view/1089/2385

Nielsen, J. (2006). Participation inequality: Encouraging more users to contribute. Jakob Nielsen's Alertbox, 9. Retrieved from https://www.nngroup.com/articles/participationinequality/

Otte, E., \& Rousseau, R. (2002). Social network analysis: A powerful strategy, also for the information sciences. Journal of Information Science, 28(6), 441-453. https://doi.org/10.1177/016555150202800601

Ruberg, L. F., Moore, D. M., \& Taylor, C. D. (1996). Student participation, interaction, and regulation in a computer-mediated communication environment: A qualitative study. Journal of Educational Computing Research, 14(3), 243-268.

Russo, T. C., \& Koesten, J. (2005). Prestige, centrality, and learning: A social network analysis of an online class. Communication Education, 54(3), 254-261.

Siemens, G. (2004). Connectivism: A learning theory for the digital age. International Journal of Instructional Technology and Distance Learning, 2(1), 3-10. Retrieved from http://www.itdl.org/journal/jan_05/article01.htm

Siemens, G., \& Downes, S. (2011, January). What is connectivism? [Web log comment]. Retrieved from http://cck11.mooc.ca/how.htm

Soliman, M., Nasraoui, O., \& Cooper, N. G. F. (2016). Analysis and visualization of a literaturemined glaucoma gene interaction network. Proceedings of the IEEE/ACM International Conference on Advances in Social Networks Analysis and Mining (ASONAM) (pp. 669676). doi:10.1109/ASONAM.2016.7752309

Thomas D. R. (2003). A general inductive approach for qualitative data analysis. School of Population Health, University of Auckland. Retrieved from http://www.frankumstein.com/PDF/Psychology/Inductive $\% 20$ Content $\% 20$ Analysis. pdf

Wong, J.-S., Pursel, B., Divinsky, A., \& Jansen, B. J. (2015). An analysis of MOOC discussion forum interactions from the most active users. In N. Agarwal, K. Xu, \& N. Osgood (Eds.), Social computing, behavioral-cultural modeling, and prediction (pp. 452-457). Switzerland: Springer International Publishing. http://doi.org/10.1007/978-3- 319-16268$\underline{3 \quad 58}$

Young, J. R. (2012). Providers of free MOOC's now charge employers for access to student data. Chronicle of Higher Education. Retrieved from http://chronicle.com/article/ProvidersofFreeMOOCsNow/136117/ 